\title{
Social Support and Health: A Theoretical Formulation Derived from King's Conceptual Framework
}

\author{
Maureen A. FreY, RN; PHD*
}

\begin{abstract}
This article describes the development and initial empirical testing of a theoretical formulation of social support, family, health, and child health derived from Imogene King's conceptual framework for nursing. A correlational design was used to test the formulation with 103 families who have children with diabetes mellitus. Three hypotheses were supported: parents' social support had a direct and positive effect on family health, parents' social support and child's social support were positively related, and illness factors had a direct and negative effect on child health. Both the supported and unsupported hypotheses are discussed in terms of the present substantive knowledge base and evidence of validity for King's framework. Direction for further theory development and research are identified.
\end{abstract}

The 1980s may well be known as the decade of social support. Nursing, like other health sciences, has moved from debating the direct versus indirect effect of social support on health to incorporating the concept of social support into existing and new theoretical formulations. As a result, an impressive body of knowledge of the mechanisms by which social support influences health is developing in such areas as transition to parenthood, teenage pregnancy outcome, fetal attachment, infant attachment, maternal discipline, and parenting of developmentally delayed infants (Barnard, Brandt, Raff, \& Carroll, 1984).

This article describes the development and initial empirical testing of a theoretical formulation of social support, family health, and child health in families who have children with insulin dependent diabetes mellitus (IDDM). The proposed formulation makes several significant contributions to the existing knowledge base of social support and health

Key Words: Soctal Support, Health, King's Conceptual Framework

Received September 6, 1988.

Accepted October 25, 1988.

- University of Michigan, Ann Arbor, MI.

The study on which this article is based was partially funded by the American Nurses' Foundation, Michigan Nurses' Association, and a predoctoral fellowship from the American Diabetes Association-Michigan Affiliate, Inc.

The author wishes to acknowledge Jacqueline Campbell, R.N.; Ph.D., for her critique of the article.

0894-3184/89/0203-0138\$02.00/0

Nursing Science Quarterly

Copyright $₫$ by Williams \& Wilkins for nursing practice. First, few theory or research models specifically incorporate family and child variables. Although the effect of social support on the family has been increasingly addressed, very little is known about social support and its effects on child health or the relationship between parent support and child support. Second, the context for the research is families with children with a chronic illness. Social support has been extensively investigated in relation to the onset of various diseases, cumulative life events, and recovery from acute illness episodes. However, less attention has been given to the role of support in chronic illness either for individual adults, children, or family units.

In addition to addressing an important substantive area for nursing knowledge, an additional aim of the research was to determine or test the underlying validity of King's conceptual framework. Empirical testing of middle range theories derived from conceptual frameworks contributes indirect evidence as to the credibility of the conceptual framework (Fawcett, 1989; Silva, 1986). Further, this process of theory development is likely to result in knowledge unique to the discipline of nursing (Phillips, 1988; Whall \& Fawcett, 1988).

\section{Development of the Theoretical Formulation}

The theoretical formulation was explicitly guided by King's conceptual framework. King's framework served as a basis for conceptual definitions of concepts, identifying empirical indicators of concepts, and proposing relationships among concepts. Since con- 
ceptual frameworks are broad, abstract, and not specific to populations and practice settings, additional theoretical and empirical evidence was also used in development of the formulation.

King's conceptual framework consists of three interacting, open systems: individuals as personal systems, two or more individuals forming interpersonal systems, and larger groups with common interests and goals forming social systems. Many concepts, borrowed from other disciplines and redefined by King, are used to identify relevant knowledge for understanding each system. Definitions and relationships in this formulation are derived from King's concepts of health and interaction.

\section{Child and family health}

In the present study, child health is conceptualized from King's (1981) concept of health in relation to the personal system. King defines health as a process of growth and development and the ability to function in social roles. Health has biological, psychological, and social dimensions. From King's perspective, health and illness are both dimensions in the life events of human beings. The distinction between health and illness is often arbitrary and influenced by such factors as one's culture, definition of health, perception of health, and environment. Illness indicates interference in the life cycle and is defined as an imbalance in a person's biological structure, psychological make-up, or social relations.

For this formulation, child health is theoretically defined as developmentally appropriate physical, biological, psychological, and social functioning. This definition is consistent with King's view of health. Recognition of developmental level was identified by King as an attribute of health, and is included in the definition in order to differentiate child health from adult health.

Family health is conceptualized from King's $(1981,1983)$ concept of health in relation to social systems. The family is identified as a basic structural and functional unit of society and the primary social environment for the individual. Family health is also viewed in terms of functional ability. A functional or healthy family is able to adjust to stressors in the internal and external environment and cope with maturational and situational crises (King, 1983).

Although King does not offer a conceptual definition of family health, she does indicate that the concept of health can be applied to the family as a social system. For this formulation, family health is theoretically defined as the adaptive potential and functional ability of the family in terms of performance of social roles. From King's perspective, this would in- clude structural and functional dimensions of the family system. Other indicators of family health could be extrapolated from the additional concepts that King identified as important for understanding social systems: organization, authority, power, status, decision making, and control (King, 1981). King's use of general systems and structural-functional concepts to evaluate family health, and the interchangeable use of the terms family health and family functioning, is consistent with the work of other family scholars (Barnhill, 1979; Feetham, 1984; Minuchin, 1974; Olson, Sprenkle, \& Russell, 1979).

\section{Social support}

Social support is conceptualized from King's (1981) concept of interaction for interpersonal systems. King placed the concept of interaction within the interpersonal system because interaction occurs between two or more persons. Each interaction involves verbal and nonverbal communication and is characterized by values. Communication is defined by King as an exchange of information. Interactions also include exchange of either material goods or services. According to King, interaction is essential in developing relationships. It is through relationships that growth, change, and personal development take place. Therefore, the quality of interactions may have a positive or negative influence on health.

The multiple definitions of social support in the literature are consistent with what King (1981) describes as the content of interaction. For example, Cobb (1976) defined social support as information leading one to believe she or he is cared for or loved, esteemed or valued, and part of a network of communication and mutual aid. Kahn and Antonucci (1980) identified social support as interpersonal transactions that included the expression of positive affect, affirmation of behavior, or material aid to another person. Weiss (1974) proposed that social support included the provision of attachment, social integration, nurturance, reassurance of worth, a sense of reliable alliance, and obtaining guidance through social relationships. House (1981) defined social support as interpersonal transactions involving emotional concern, information, appraisal, or instrumental aid.

Several nurse scientists have addressed the definitional diversity surrounding the construct of social support. In reviewing multiple definitions of social support, MacElveenHoehn and Eyres (1984) found that House's (1981) four categories tended to account for most of the descriptive terms used by others in relation to the content of social support. Diamond and Jones (1983) attempted an integrative approach to a theoretical definition of social support. Four points on which various 
definitions converged were identified: communication of positive affect, a sense of social integration, reciprocity of directedness as a factor in the continuance of support and satisfaction in interaction, and the provision of tangible aid.

Despite definitional diversity, it seems fairly well established that social support is conceptualized as a component of social interaction with family, friends, neighbors, and others with whom one has personal contact. The elements of exchange of communication and aid, reciprocity, and mutuality are consistent with King's (1981) view of the content and character of interactions.

Social support is theoretically defined as an exchange of positive affect, a sense of social integration, emotional concern, and/or direct aid or services between two persons. Since, according to King, the quality of interactions influences health, the quality of social support, as a component of social interaction, also would be expected to influence health.

\section{Social support and family health}

In specifying the relationship between interaction (social support in this formulation) and health, King did not distinguish between the health of personal systems (individuals) and social systems (families). Extensive empirical evidence supports the generally positive effect of social support on individual health and functioning (Berkman \& Syme, 1979; Gottlieb, 1983; Hyman \& Woog, 1982). Perhaps because of the evidence indicating the generally positive effects of social support on the health of individual adults, increased attention has been directed toward social support and the family unit. In general, support of the nuclear family from immediate or extended kin as well as from friends, work associates, neighbors, and the community has been increasingly recognized as a factor that influences family wellbeing and behavior (Anderson, 1982; Pilisuk \& Parks, 1983; Unger \& Powell, 1980). Thus, it is postulated that support for the family (parents' support) has a direct and positive effect on family health.

\section{Social support and child health}

King's framework does not explicitly differentiate between children and adults. As a result, the framework offered little direction as to the nature of the relationships between parents' support and child's support and child's support and child's health. However, Cochran and Brassard's (1979) conceptual model of relationships between child development and the personal social networks of immediate family members provides a perspective for viewing these relationships. Although focused on network analysis, which is different from social support, social support was clearly iden- tified as a major function of the network by these authors.

According to Cochran and Brassard (1979) direct network influences come to the child through the variety and range of persons with whom the child has contact on a recurring basis, either independently or with other family members. It is through the parents' social network that children are exposed and provided access to opportunities for interaction, different environmental settings, and new stimuli. From a developmental perspective, the younger the child, the more likely this is to be true.

Other influences come to the child indirectly via the family system, more specifically through the impact of network members on adult functioning in the parenting role (Cochran \& Brassard, 1979). Several studies investigated social support for young children and infants via various family and parent behaviors (Brandt, 1984; Pascoe \& Earp, 1984; Zelkowski, 1987). However, there has been very little investigation of social support for older children or adolescents.

One additional outcome for children as a result of direct and indirect influences of the parents' social network is the development of the child's own network building skills (Cochran \& Brassard, 1979). The notion of reciprocal exchange is learned through social interaction. Cochran and Brassard suggest that the nature of roles and power structures within families is such that the opportunity to practice and observe these exchanges is limited. Therefore, development of the concept of reciprocity is dependent on observation of parent exchanges with network members and access to an arena in which to practice exchanges. This link between the parents' and child's social network would have added significance in later developmental stages when peer relationships increasingly influence child behavior.

In the present formulation, it is hypothesized that a child's social support directly and positively influences child health and that parents' support and child's support are positively related. These relationships are extrapolated from adult models of social support for individuals, the theoretical perspective of Cochran and Brassard (1979), and in consideration of the older child and adolescent's developmental level.

To summarize, the concepts of health and interaction from King's conceptual framework for nursing were used as the basis for theoretical definitions of child health, family health, and social support. The linkages or-relationships among these concepts were derived from King's framework as well as additional theoretical and empirical literature. The new, theoretical formulation of social support and health is shown in Figure 1. The hypotheses 


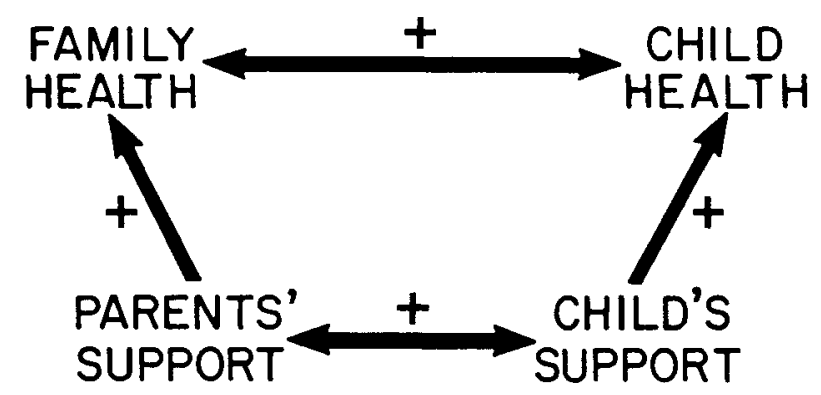

Figure 1. Hypothesized relationships among concepts.

tested were as follows:

1. There is a positive and reciprocal relationship between family health and child health.

2. Parents' support has a direct and positive effect on family health.

3. Child's support has a direct and positive effect on child health.

4. There is a positive and reciprocal relationship between parents' support and child's support.

\section{Methodology}

\section{The target population}

Families with children with IDDM were selected as the target population because IDDM is an example of a chronic condition that has long term, but not fatal, implications for the health of the family and child. For the family, there is monitoring of physiological symptoms, management of the medical regime, and responsibility for day to day decision making. For the child, there is daily insulin injections, urine or blood glucose testing, and dietary restrictions. The goals of treatment for diabetic children are threefold: the children should feel good, function normally, and have stable glucose metabolism or metabolic control. Although not curable, administration of exogenous insulin should correct the metabolic deficit. However, multiple psychosocial factors, including structural and functional characteristics of the family system, have been associated with adverse child health outcome in this population (Anderson, Auslander, Miller, \& Santiago, 1981; Minuchin et al. 1975; Orr, Golden, Myers, \& Marrero, 1983; White, Kohlman, Wexler, Polin, \& Winter, 1984).

Interpretation of and generalizations from empirical findings have been limited by methodological and theoretical issues (Anderson \& Auslander, 1980; Johnson, 1980). With few exceptions (see Anderson et al. 1981, Minuchin et al. 1975; Newbrough, Simpkins, \& Maurer, 1985), family-child relationships had not been approached from a theoretical perspective. Metabolic control was the most frequent and often the only indicator of child health. A major limitation of diabetes related research has been the lack of attention to other variables that might influence or explain the relationship between family factors, child factors, and metabolic control, especially family interactions or linkages beyond the family system.

Social support for diabetic youths had not been extensively examined. However, difficulty with social relations with peers, at school, and in the home had been reported in the literature (Orr et al. 1983). The relationship with the health care team was identified as a concern of parents of diabetic youths (Hodges \& Parker, 1987). Overall, there had been little systematic examination of social support for the child or family unit in this population despite an identified need to do so.

King's conceptual model offers a useful structure for examining the relationships among family, child, and environmental variables in families with children with IDDM. The general systems perspective directs attention to factors outside the family that potentially have an impact on family and child behavior. Additionally, King stresses the relationships between interaction with the environment and health as an important focus for nursing research and practice. King (1981) states:

An understanding of the ways that human beings interact with their environments to maintain health is essential for nurses; this enables these professionals to promote health, to prevent disease, and to care for ill or disabled people (p. 2).

Overall, King's framework is both useful and appropriate for examining social support and health in this population.

\section{Sample}

For this descriptive, correlational design a convenience sample of 103 families with diabetic children between the ages of 10 to 16 was used. Additional criteria for entering the study were that (a) the child had been diagnosed for at least 6 months, (b) the parents and child were able to read at a 5 th grade level, (c) the parents and child had no obvious developmental or physical handicap, and (d) the child had no other chronic illness. All families were English speaking. The sample was obtained from the medical practice of several pediatricians and pediatric endocrinologists and the diabetic clinic of a university hospital in the midwest. Selected demographic characteristics of the sample are shown in Table 1 .

\section{Operationalization}

Two indicators of family health (functional and structural) were selected for this study based on King's structural-functional and general systems perspective of the family. The functional indicator was family functioning. Family functioning was operationalized as the "Family Distance from the Center" score determined by parent and child scores on the Fam- 
Table 1

Demographic Characteristics of the Sample

\begin{tabular}{lrr}
\hline \multicolumn{1}{c}{ Characteristic } & $M$ & $S D$ \\
\hline Children $^{\mathrm{a}}$ & & \\
Age & 13.75 & 2.09 \\
Age at diagnosis & 8.44 & 3.33 \\
Length of illness (years) & 5.37 & 3.07 \\
Parents & \\
Mother's education (years) & 13.48 & 2.28 \\
Father's education (years) & 13.73 & 3.00 \\
Religious preference & $54 \%$ & \\
Protestant & $43 \%$ & \\
Catholic & $3 \%$ & \\
Other & & \\
Ethnic affiliation & $23 \%$ & \\
Black & $68 \%$ & \\
White & $9 \%$ \\
Other & & \\
Family Income (modal) & $\$ 25,000$ to $\$ 49,000$ \\
\hline
\end{tabular}

a Females $n=62$, males $n=41$.

${ }^{b}$ Mothers $n=102$, fathers $n=70$.

ily Adaptability and Cohesion Evaluation Scales (FACES) III (Olson, Portner, \& Lavee, 1985). Scoring is such that lower scores indicate more favorable family functioning.

FACES III is a 20 item scale designed to assess family adaptability and cohesion. The subconcepts that make up the adaptability and cohesion dimensions are power structure, role relationships, negotiation styles, relationship rules, feedback, emotional bonding, boundaries, coalitions, decision making, time, space, and friends (Olson et al., 1985). These subconcepts are consistent with several of the concepts King (1981) identified as important concepts for understanding social systems.

The psychometric properties of the scale have been addressed in several large studies. Internal consistency, using Cronbach's Alpha, for the adaptability and cohesion subscales and scale total were reported as $0.62,0.77$, and 0.68 , respectively (Olson et al., 1985). Test-retest reliability was reported as equal to or greater than 0.80 . In the present study, alpha coefficients for cohesion, adaptability, and scale total ranged from 0.66 to $0.79,0.70$ to 0.86 , and 0.71 to 0.76 for children, mothers, and fathers, respectively.

Family composition was an indicator of family structure which took into consideration the number, role relationship, and participation of adults in the home. Family composition was determined by parents' self-report of marital status and an open-ended interview question on persons residing in the household. Several categories of family composition were identified. The following categories were assigned the numbers 1 to 4 in order to operationalize family composition: single parent; two parent, biological or nonbiological, one parent participated; two parent nonbiological, both parents participated; and, two parent, biological, both parents participated. (There were 22, 11, 7 , and 63 families in the four family composition groups, respectively.) Higher scores are assumed to have a more favorable effect on family and child outcome as has been suggested in the literature (Egbuonu \& Starfield, 1982; Kellam, Ensminger, \& Turner, 1977).

Parents' social support was operationalized as the total functional support score on the Norbeck Social Support Questionnaire (NSSG) (Norbeck, 1984). The NSSQ was selected because it taps content dimensions of support that are consistent with King's perspective of the content of interaction. The scale also measures perceived support available which is appropriate, given King's emphasis on perceptions. The one limitation of the scale, however, is that it does not tap the reciprocity of support.

Child's social support was likewise operationalized using the child's scores. Use of the NSSQ with children has not been reported in the literature but seemed feasible given the 5 th grade reading level of the scale (Fry, 1977).

The functional support subscale consists of six items, two each for aid, affirmation, and affect. Subjects list all the important people in their life and rate each person on each item using a 4 or 5 point response scale. Scoring was done by summing the ratings for each item and adding item scores together.

Children, mothers, and fathers each completed the NSSQ. The following method for determining a parent support score was developed for this study. Scoring was done jointly for mothers and fathers in two-parent families. A person listed by both the mother and father was counted only once. The score for that person was the average of the number assigned by the mother and father. Therefore, in two-parent families, parent support measures were determined from mother and father scores; and in single parent families, parent support measures were the scores of the single parent. Higher scores indicated more support perceived to be available to the parents or child.

Psychometric properties of the NSSQ were investigated in several large studies (Norbeck, Lindsey, \& Carrieri, 1983). Internal consistency measures for the NSSQ were reported (for adult respondents) to be from 0.69 to 0.97 for the functional support subscale. In the present study alpha coefficients for the functional support subscale for mothers, fathers, and children ranged from 0.78 to 0.84 .

There were seven indicators of child health. These indicators tapped psychosocial, physical, and biological dimensions of health. The psychosocial indicators were scholastic competence, social acceptance, athletic competence, physical appearance, and self-worth operationalized as subscale mean scores on the Self-perception Profile for Children (SPPC). 
The SPPC (Harter, 1985) is designed to measure competence in age appropriate social roles and tasks in several domains of psychological and social development. As such, it is a very good fit with King's perspective of health. Higher scores indicate a more adequate selfevaluation in each domain. Reliability, using Cronbach's Alpha for the six subscales is reported as 0.71 to 0.84 . In the present study alpha coefficients ranged from 0.76 to 0.85 .

Physical symptoms were operationalized as the summative score on the Diabetic Symptom Survey (DSS). The DSS was a modification of a symptom checklist used in a previous study by Eastman, Johnson, Silverstein, Spillar, and McCallum (1983). The tool included symptoms associated with hypoglycemia and hyperglycemia identified by diabetic children. The child rated the frequency of 32 symptoms on a 5point response scale. Higher scores indicated more frequent occurrences of physical symptoms. Face validity was addressed and the tool was pretested prior to use in the study. The alpha coefficient in the present study was .90 .

Metabolic control was measured by the value of the child's hemoglobin Alc. Hemoglobin Alc (HgbAlc) is an indirect and retrospective measure of glucose metabolism over the previous 2 month period. It is considered a valid and reliable indicator of metabolic control and is extensively used for research purposes (Cohen, 1986). In general, a HgbAlc value of less than $10 \%$ is considered good metabolic control, 10 to $13 \%$ is considered fair metabolic control, and greater than $13 \%$ is considered poor metabolic control (Anderson et al. 1981).

\section{Procedures}

All families meeting eligibility criteria were contacted by this author. If the family was willing to participate, an appointment to complete the interview and questionnaires was made at the family's convenience. Data were collected during in-home interviews by trained data collectors or in the clinic if all family members designated to participate were available. Parents signed informed consent papers and children provided verbal assent at the time of data collection. Demographic data were obtained by interview. HgbAlc was obtained from the medical records. All other data were obtained from the self administered scales.

\section{Analysis of data}

The relationship among the various indicators of child health were addressed by correlational analysis and exploratory factor analysis. LISREL VI (Joreskog \& Sorbom, 1984) statistical program was used to analyze the causal model. The LISREL analysis is particularly appropriate for testing complex relationships among variables using multiple indicators
(Boyd, Frey, \& Aaronson, 1988). All analyses were done with subprograms of SPSSX (1986).

\section{Preliminary Analysis and Model Revisions}

Several revisions were made in the causal model due to a combination of technical, methodological, and theoretical limitations and constraints. First, negative correlations among the physical, biological, and psychosocial dimensions of health suggested both conceptual and measurement concerns about the indicators. That is, the indicators were not measuring a single underlying construct, a necessary requirement of LISREL analysis. Consequently, a principal component factor analysis with varimax rotation was performed with the seven child health indicators. In addition, the duration of illness and the child's age were entered into the analysis in order to determine if they were appropriate indicators of, or in some way related to, child health.

The factor analysis resulted in a three factor solution (eigenvalues $>1$ ) which accounted for $58 \%$ of the variance in child health. The psychosocial indicators loaded on the first two factors and accounted for $45 \%$ of the variance. Duration of illness, metabolic control, and child's age loaded together on the third factor. This last factor appeared to be something other than health and was subsequently labeled as illness factors. The physical symptom scale loaded on more than one factor. Because it was unclear whether the frequency of physical symptoms reported by children was a health or illness factor, it was dropped from subsequent analysis.

Based on those preliminary analyses, a major change was made in the proposed model. The psychosocial indicators remained as indicators of child health. Age, metabolic control, and duration of illness were identified as indicators of a different construct labeled illness factors. Illness factors are hypothesized to have a direct and negative effect on child health. Table 2 contains the correlations, means, and standard deviations of indicators used in the LISREL analysis.

\section{Results}

LISREL analysis provides information about the overall fit of the hypothesized model to the data, the strength and direction of the hypothesized relationships in the model, and the adequacy of the measures as indicators of constructs (Boyd, Frey, \& Aaronson, 1988). Several measures of goodness-of-fit were used to assess the extent to which the proposed model fit the data. The Relative Likelihood Ratio (RLR) is a ratio of the chi-square value to its degrees of freedom (Joreskog \& Sorbom, 1984). It may be viewed as an indicator of how the model being tested compares to an alternative, 
Table 2

Correlations, Means, and Standard Deviations of Indicators in the Causal Model

\begin{tabular}{|c|c|c|c|c|c|c|c|c|c|c|c|c|}
\hline & 1 & $2^{a}$ & 3 & 4 & 5 & 6 & 7 & 8 & 9 & 10 & 11 & $12^{\mathrm{a}}$ \\
\hline $\begin{array}{l}\text { 1. Family composition } \\
\text { 2. Family functioning } \\
\text { 3. Scholastic competence } \\
\text { 4. Social acceptance } \\
\text { 5. Behavioral conduct } \\
\text { 6. Physical appearance } \\
\text { 7. Global self-worth } \\
\text { 8. Parents' general support } \\
\text { 9. Child's general support } \\
\text { 10. Age } \\
\text { 11. Duration of illness } \\
\text { 12. Metabolic control } \\
M \\
\text { SD }\end{array}$ & $\begin{array}{c}-0.27^{\mathrm{a}} \\
0.05 \\
0.03 \\
-0.05 \\
-0.12 \\
-0.03 \\
0.53 \\
0.22 \\
-0.11 \\
0.02 \\
-0.45^{\mathrm{a}} \\
3.08 \\
1.26\end{array}$ & $\begin{array}{l}- \\
-0.07 \\
-0.18^{\mathrm{a}} \\
-0.03 \\
-0.05 \\
-0.15 \\
-0.17 \\
-0.01 \\
0.09 \\
0.17 \\
0.23 \\
5.76 \\
3.71\end{array}$ & $\begin{array}{r}- \\
0.19 \\
0.44 \\
0.28 \\
0.45 \\
-0.01 \\
0.07 \\
-0.03 \\
-0.23 \\
-0.12 \\
3.02 \\
0.69\end{array}$ & $\begin{array}{r}- \\
0.08 \\
0.31 \\
0.33 \\
-0.07 \\
-0.01 \\
-0.22 \\
-0.25 \\
0.12 \\
3.01 \\
0.66\end{array}$ & $\begin{array}{r}- \\
0.22 \\
0.46 \\
-0.02 \\
0.23 \\
-0.08 \\
-0.11 \\
0.01 \\
3.10 \\
0.60\end{array}$ & $\begin{array}{r}- \\
0.61 \\
-0.15 \\
-0.10 \\
-0.24 \\
-0.29 \\
-0.05 \\
2.75 \\
0.76\end{array}$ & $\begin{array}{r}- \\
-0.03 \\
0.06 \\
-0.01 \\
-0.27 \\
-0.04 \\
3.16 \\
0.60\end{array}$ & $\begin{array}{r}- \\
0.32 \\
-0.04 \\
-0.02 \\
-0.09 \\
246.83 \\
84.82\end{array}$ & $\begin{array}{r}- \\
-0.14 \\
0.01 \\
0.01 \\
223.02 \\
89.90\end{array}$ & $\begin{array}{c}-\overline{0} \\
0.20 \\
0.29^{\mathrm{a}} \\
13.74 \\
2.09\end{array}$ & $\begin{array}{l}-\overline{-} \\
0.29 \\
5.37 \\
3.07\end{array}$ & $\begin{array}{r}- \\
11.62 \\
2.94\end{array}$ \\
\hline
\end{tabular}

${ }^{\mathrm{S}} \mathrm{S}$ coring is such that lower scores are more positive outcome; $r \geqslant 0.17, p<0.05 ; r \geqslant 0.23, p<0.01$.

unconstrained model. Ratios in the range of 2 to 1 or 3 to 1 are considered indicative of good fit (Carmines \& McIver, 1981).

Joreskog and Sorbom (1984) also developed a Goodness-of-fit Index (GFI) which measures the relative amount of variance and covariance jointly accounted for by the model. A GFI in the $0.90 \mathrm{~s}$ is considered to indicate good fit.

The proposed model had a $\chi^{2}$ of 106.23 with $51 d f$ for a RLR of 2.08 to 1 . The GFI for the proposed model was 0.87 . The GFI indicated adequate fit, and the RLR indicated good fit of the model to the data. The coefficient of determination, a measure of the strength of all structural relationships jointly (Joreskog \& Sorbom, 1984), was 0.42 . Although acceptable, this suggests that a moderate amount of the variation in family health and child health was due to factors outside of the model.

Figure 2 shows the results of the LISREL analysis. The causal and noncausal relationships between the concepts are standardized maximum likelihood (ML) estimates and are analogous to path coefficients and correlations. The structural parameters, representing hypothesized relationships, are tested with the $t$ statistic (Joreskog \& Sorbom, 1984).

Three of the five hypotheses were supported: parents' social support had a direct and positive effect on family health (hypothesis 2); parents' and child's social support were significantly related (hypothesis 4); and, illness factors had a direct and negative effect on child health (hypothesis 5, added after model revision). The reciprocal relationship between family health and child health (hypothesis 1) was not supported, nor was the direct effect of child's support on child health (hypothesis 3 ).

\section{Discussion}

The findings provide some empirical support for the theoretical formulation of social support and health in families with children with
IDDM and, therefore, indirect validation of King's conceptual framework for nursing. In addition, the findings provide direction for further theory development and research with this, and perhaps other, clinical populations.

\section{Social support and health}

Two hypotheses were tested in relation to social support and health: social support for parents in relation to family health, and social support for children in relation to child's health. It was predicted and supported that parents who perceived higher amounts of available support had significantly $(t=4.87$, $p<0.05$ ) higher levels of family health. This is consistent with findings identified in both the social support and family health literature (Pilisuk \& Parks, 1983; Pratt, 1976; Unger \& Powell, 1980). Since this relationships was derived from the propositions of King's conceptual framework, the findings provide partial empirical support for the relationship between interaction and health. The findings are also evidence of the interacting relationship between the interpersonal system (social support) and social systems (the family) as predicted by King's framework.

The hypothesized relationship between child's social support and child's health was not supported by the study findings. King did not differentiate between adults and children in conceptualizing the relationship between interaction and health. Although there is ample evidence of the generally positive effect of social support on adult health, there was a dearth of theoretical or empirical knowledge about social support in older children and how social support influenced child health. As a result, this hypothesis was tentative, at best.

In retrospect, there were several factors that may have accounted for the lack of relationship between child's support and child's health. From a theoretical perspective, it may not have been appropriate to infer from adult 


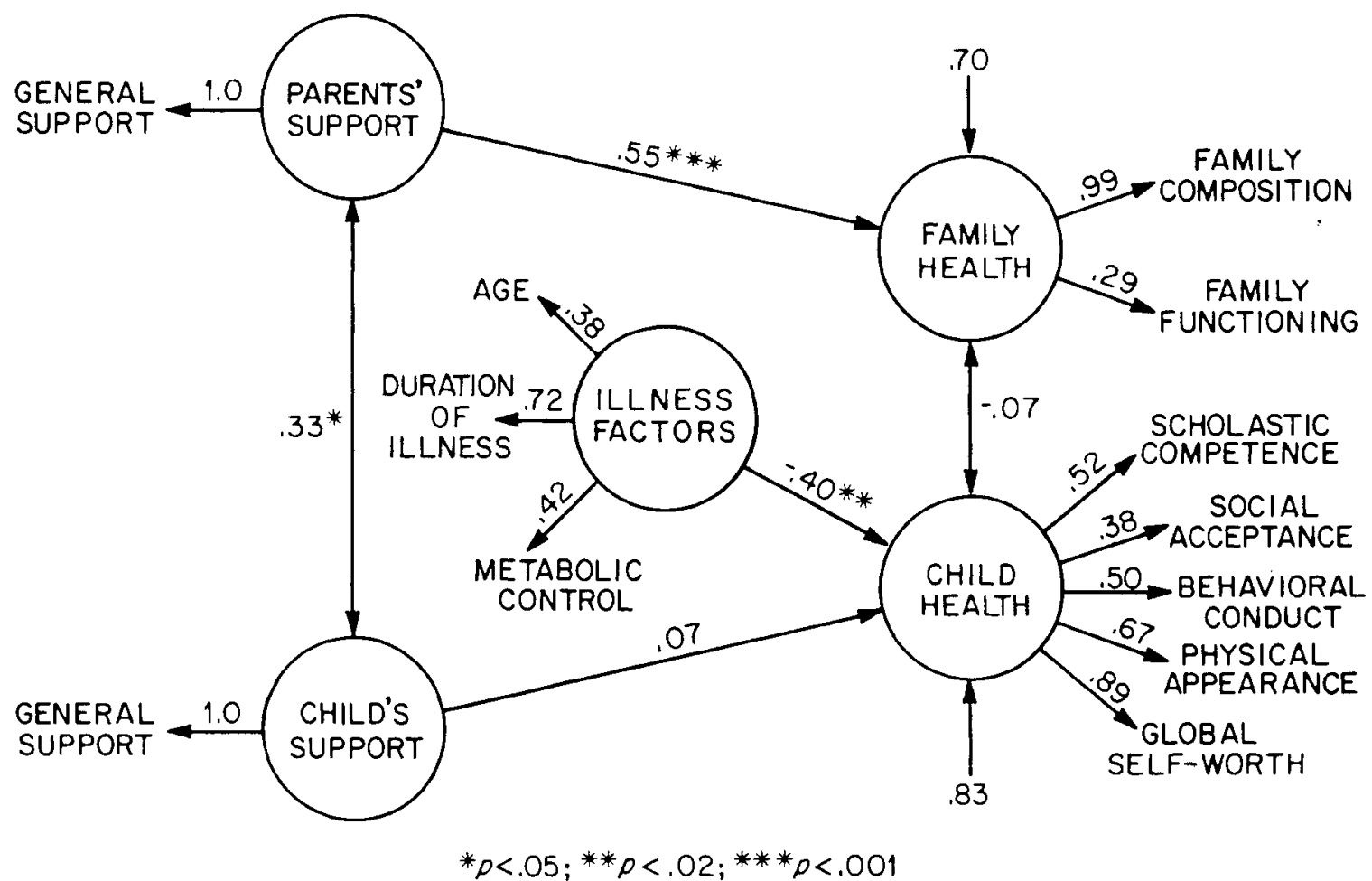

Figure 2. Causal model with maximum likelihood estimates.

models of social support and health to a child model. It could also be that support for the parents directly influenced child health, a relationship that was not tested in this formulation. The importance of supportive actions by parents was described in the IDDM literature which does suggest a direct effect (Bobrow, AvRuskin, \& Siller, 1985; Schafer, Glasgow, McCaul, \& Dreher, 1983). However, the link between support for parents, supportive actions by parents, and child health was difficult to interpret from previous research, due to inconsistent conceptualization and measurement of support and child health. Clearly, this is an important area for further research.

\section{Parent's support and child's support}

A significant $(t=3.13, p<0.05$ ) relationship also occurred between parents' support and child's support as hypothesized. Higher levels of general support available to parents' were associated with higher levels of general support available to children.

Again, King (1981) did not differentiate between interaction (social support in the formulation) for children as opposed to adults. The hypothesized relationship was based on the theoretical model proposed by Cochran and Brassard (1979) and consideration of the developmental level of the youths in the population being studied. No studies were found that described relationships between support for parents', and support for children in schoolaged or older youths so empirical evidence for the hypothesized relationship was also lacking.
The findings relating parents' social support and child's social support have both substantive and theoretical import. First, this is an important extension of the knowledge base of social support for nursing and other disciplines. The findings also suggest that the difficulties with social relationships reported in the literature for some diabetic youths may be more related to the social skills learned within the family environment than to the illness!

\section{Family health and child health}

The hypothesized relationship between family health and child health also was not supported by the study findings. The lack of a significant relationship between family health and child health was unexpected because it had strong theoretical support. This relationship was predicted based on King's (1981) general systems perspective, particularly the family serving as the primary environment for the developing child. The lack of empirical support for the relationship in this formulation probably was due to a combination of factors.

One potential difficulty may have been with selection of indicators of the constructs. Although the use of multiple indicators to measure constructs is a strength of LISREL analysis, selecting an adequate number of appropriate indicators is somewhat of an art (Bentler, 1980). The measurement properties of family health might be improved by using more than two indicators. Some of the difficulty could also have been due to an incomplete conceptualization of child health. After dropping the physical symptom measure, the remaining in- 
dicators tapped only the psychosocial dimensions of health. Additional indicators of other dimensions of health need to be identified. In addition, evaluation of self-perceived health status would be especially relevant given King's emphasis on perceptions.

Aside from the measurement and conceptual issues, it is very possible that the relationship between family health and child health was not a direct effect as hypothesized. It could be the case that family health has an indirect effect on child health. The formulation, as tested, did not permit examination of indirect effects. Clearly, there is a need to expand the parameters of the formulation. Again, based on reexamination of the literature, self-care in relation to diabetic management may be an important variable linking family health, parents' support, child's support, and child health in this population.

\section{Illness and health}

Although serendipitous, the negative and significant ( $t=2.53, p<0.05$ ) effect of illness factors on child health also provides support for King's conceptual framework. King (1981) says that illness was one factor that influences health. For this sample, youths who had IDDM longer, were older, and had poorer metabolic control had less adequate psychosocial health.

In addition to supporting King's framework, the findings reinforce the postulate that nursing knowledge of health depends on a clear conceptualization of health and cannot be inferred from the absence of overt pathology. From review of the IDDM literature, health was generally defined by medical standards. In view of nursing's multidimensional view of health (Reynolds, 1988; Smith, 1983), knowledge generated to date may not be sufficient as a basis for nursing practice. However, aspects of disease and illness are of concern to nursing because they influence health. Although inclusion of both health and illness indicators is a strength of this formulation and King's framework, additional attention needs to be directed toward illness indicators at both the conceptual and operational level.

\section{Summary and Conclusions}

Social support has emerged as an important determinant of the health and functioning of families and individuals. Interest in social support is shared by nursing and other health sciences. In order to incorporate concepts of social support into nursing practice, a sound knowledge base of how and under what conditions social support influences health is needed.

The purpose of the study described here was to generate and test a theoretical formulation of social support, family health, and child health in families with children with IDDM. An additional aim of the study was to validate King's (1981) conceptual framework for nursing. King's conceptual framework was used as the basis for defining, selecting indicators, and proposing relationships among the concepts. Additional theoretical perspectives and the empirical findings from the IDDM literature were considered in development of the formulation. This process of developing middle range theories from nursing's broader conceptual frameworks has particular utility for generating knowledge unique to the discipline of nursing.

Initial testing of the formulation demonstrated the positive effect of parents' social support on family health, the negative effect of illness factors on child health, and the positive and reciprocal relationship between parents' support and child's support. These findings provide empirical evidence which supports King's conceptual framework in relation to the effect of interaction on health, at least for adults. In addition, the findings extend the knowledge base of social support and health for nursing in a context that had not been extensively addressed in the literature.

Several of the hypothesized relationships were not supported. The lack of a significant relationship between family health and child health, and child's support and child health in the present study seemed primarily related to selection and measurement of indicators and to several missing variables that might explain or mediate the relationships. This lack of relationship seemed less related to the theoretical relationships predicted by King's (1981) conceptual framework. Based on the findings of this study, new directions for expanding and refining the research model were identified. At the present time, this author is testing a model that includes child's self-care as an intervening variable between family health and child health and child's social support and child health. Additional indicators of child health and illness are being used in order to address the limitations identified as a result of preliminary testing of the formulation.

In conclusion, development and testing of a middle range theory of social support, family health, and child health has made a contribution to the knowledge base of professional nursing. Several concepts which were of interest to other disciplines were investigated from a nursing perspective. The proposed formulation should be viewed as a preliminary approximation of a more complex process. However, simplification of complex relationships is both useful and necessary especially in the early stages of theory building and testing. Although additional studies are needed, nursing is closer to understanding the complex nature of the relationship between the social environment and health. 


\section{References}

Anderson, C. (1982). The community connection: The impact of social networks on family and individual functioning. In F. Walsh (Ed.), Normal Family Process, (pp. 425-445). New York: Guilford Press.

Anderson, B. J., \& Auslander, W. F. (1980). Research on diabetics management and the family: A critique. Diabetes Care, 3, 696-702.

Anderson, B. J., Miller, J. P., Auslander, W. F., \& Santiago, J. V. (1981). Family characteristics of diabetic adolescents: Relationship to metabolic control. Diabetes Care. 4, 586-594.

Barnhill, L. R. (1979). Healthy family systems. The Family Coordinator, 28, 94-100.

Barnard, K. E., Brandt, P. A., Raff, B. S., \& Carroll, P. (Eds.), (1984). Social support and families of vulnerable infants. New York: March of Dimes Birth Defects Foundation.

Bentler, P. M. (1980). Multivariate analysis with latent variables: Causal modeling. Annual Review of Psychology, 31, 419-456.

Berkman, L. F., \& Syme, S. L. (1979). Social networks, host resistance, and mortality: A nine-year follow-up study of Alameda County residents. American Journal of Epidemiology, 109, 186-204.

Bobrow, E. S., AvRuskin, T. W., \& Siller, J. (1985). Motherdaughter interaction and adherence to diabetes regimes. Diabetes Care, 8, 146-151.

Boyd, C. J., Frey, M. A., \& Aaronson, L. S. (1988). Structural equation models and nursing research: Part I. Nursing Research, 37, 249-252.

Brandt, P. A. (1984). Stress-buffering effects of social support on maternal discipline. Nursing Research, 33. 229-234.

Carmines, E. G., \& Mclver, J. P. (1981). Analyzing models with unobserved variables: Analysis of covariance structures. In G. H. Bohrnstedt \& D. C. Borgatta (Eds.) Social measurement: Current issues, (pp. 65-115). Beverly Hills, CA: Sage.

Cobb, S. (1976). Social support as a moderator of life stress. Psychosomatic Medicine, 39, 300-313.

Cochran, M. M., \& Brassard, J. A. (1979). Child development and personal social networks. Child Development. $50,601-616$.

Cohen, M. (1986). Diabetes and protein glycosylation: Measurement and biological relevance. New York: Springer Verlag.

Diamond, M., \& Jones, S. L. (1983). Social support: A review and theoretical integration. In P. L. Chinn (Ed.). Advances in nursing theory development (pp. 235249). Rockville, MD: Aspen.

Eastman, B. G., Johnson, S. B., Silverstein, J., Spillar, R. P., \& McCallum, M. M. (1983). Understanding hypoand hyperglycemia by youngsters with diabetes and their parents. Journal of Pediatric Psychology, 8, 229243.

Egbuonu, L., \& Starfield, B. (1982). Child health and social status. Pediatrics, 69, 550-557.

Fawcett, J. (1989). Analysis and evaluation of conceptual models of nursing (2nd ed.). Philadelphia: F. A. Davis.

Feetham, S. L. (1984). Family research: Issues and directions for nursing research. In $\mathrm{H}$. $\mathrm{H}$. Werley, \& J. J. Fitzpatrick (Eds.). Annual review of nursing research (Vol. 2, pp. 2-25). New York: Springer.

Fry, E. B. (1977). Fry's readability graph: Clarification, validity, and extensions to level 17. Journal of Reading. 249.

Gottlieb. B. H. (1983). Social support strategies: Guidelines for mental health practice. Beverly Hills. CA: Sage.

Harter, S. (1985). Manual for the self-perception profile for children. Colorado: University of Denver.

Hodges, L. C.. \& Parker, J. (1987). Concerns of parents with diabetic children, Pediatric Nursing, 13, (1) 2228.

House, J. S. (1981). Work stress and social support.
Reading. MA: Addison-Wesley.

Hyman, R., \& Woog, P. (1982). Stressful life events and illness onset: A review of crucial variables. Research in Nursing and Health. 5, 155-163.

Johnson, S. B. (1980). Psychosocial factors in juvenile diabetes: A review. Journal of Behavioral Medicine, 3 , 95- 116.

Joreskog, K. G., \& Sorbom, D. (1984). LISREL VI analysis of linear structural relationships by the method of maximum likelihood. Mooresville, IN: Scientific Software.

Kahn, R. L., \& Antonucci, T. C. (1980). Convoys over the life course: Attachment, roles and social support. In P. Baltes \& O. Brim (Eds.), Life-span development and behavior, (pp. 251-286). New York: Academic Press.

Kellam, S. G., Ensminger, M. E., \& Turner, R. J. (1977). Family structure and the mental health of children. Archives of General Psychiatry, 34, 1012-1022.

King, I. (1981). A theory for nursing: Systems, concepts. process. New York: John Wiley \& Sons.

King, I. (1983). King's theory of nursing. In I. Clements \& F. Roberts (Eds.), Family health: A theoretical approach to nursing care. (pp. 177-188). New York: John Wiley \& Sons.

MacElveen-Hoehn, P., \& Eyres, S. J. (1984). Social support and vulnerability: State of the art in relation to families and children. In K. E. Barnard, P. A. Brandt, B. S. Raff, \& P. Carroll (Eds.). Social support and families of vulnerable infants. New York: March of Dimes Birth Defects Foundation.

Minuchin, S. (1974). Families and family therapy: A structural approach. Cambridge, MA: Harvard Univ. Press.

Minuchin, S., Baker, L., Rosman, B. L., Liebman, R., Milman, L., \& Todd, T. C. (1975). A conceptual model of psychosomatic illness in children. Archives of General Psychiatry, 32, 1031-1038.

Newbrough. J. R., Simpkins, C. G., \& Maurer. H. (1985). A family developmental approach to studying factors in the management and control of childhood diabetes. $D i$ abetic Care, 8, 83-92.

Norbeck, J. S. (1984). The Norbeck social support questionnaire. In K. E. Barnard, P. A. Brandt, B. S. Raff, \& P. Carroll (Eds.), Social support and families of vulnerable infants (pp. 45-57). New York: March of Dimes Birth Defects Foundation.

Norbeck, J. S., Lindsey, A. M., \& Carrieri, V. L. (1983). Further development of the Norbeck social support questionnaire: Normative data and validity testing. Nursing Research, 32, 4-9.

Olson, D. H., Portner, J., \& Lavee, Y. (1985). FACES III. St. Paul: University of Minnesota Press.

Olson, D. H., Sprenkle, D., \& Russell, C. (1979). Circumplex model of marital and family systems I: Cohesion and adaptability dimensions. family types and clinical application. Family Process, 18, 3-28.

Orr, D. P., Golden, M. P., Myers, G., \& Marrero, D. G. (1983). Characteristics of adolescents with poorly controlled diabetes referred to a tertiary care center. Diabetes Care, 6, 170-175.

Pascoe, J. M., \& Earp. J. A. (1984). The effect of mother's social support and life changes on the stimulation of their children in the home. Public Health Briefs, 74 , 358-362.

Phillips, J. R. (1988). The reality of nursing research. Nursing Science Quarterly, 1, 48-49.

Pilisuk, M., \& Parks, S. H. (1983). Social support and family stress. Marriage and Family Review, 6, 137156.

Pratt, L. (1976). Family structure and effective health behavior: The energized family. Boston: Houghton Mifflin.

Reynolds, C. L. (1988). The measurement of health in nursing research. Advances in Nursing Sclence, 10(4), 23-31.

Schafer, L. C., Glasgow, R. E., McCaul, K. D., \& Dreher, M. (1983). Adherence to IDDM regimes: Relationship to psychosocial variables and metabolic control. Diabetes 
Care, 6, 493-498.

Silva. M. (1986). Research testing nursing theory. Advances in Nursing Sctence, 9(1), 1-11.

Smith. J. (1983). The idea of health: Implications for the nursing profession. New York: Teachers College Press.

SPSSX users gutde (2nd ed.). (1986). New York: McGrawHill.

Unger, D. G., \& Powell, D. R. (1980). Supporting families under stress: The role of social networks. Family Relations, 29, 566-574.

Weiss, R. S. (1974). The provisions of social relationships. In Z. Rubin (Ed.), Doing unto others (pp. 23-24). Engle- wood Cliffs, NJ: Prentice-Hall.

Whall, A., \& Fawcett, J. (1988, May). Family theory development in nursing: State of the act and science. Paper presented at the International Family Nursing Conference, Calgary, Alberta, Canada.

White, K., Kohlman, M. L., Wexler, P., Polin, G., \& Winter. R. J. (1984). Unstable diabetes and unstable families: A psychosocial evaluation of diabetic children with recurrent ketoacideosis. Pediatrics, 99, 41-45.

Zelkowski, P. (1987). Social support and aggressive behavior in young children. Family Relations, 36(2), 129 134.

\section{ENRS SECOND ANNUAL RESEARCH CONFERENCE}

The Second Annual Research Conference entitled, "Approaches to Nursing Research: Are We Advancing Nursing Science?" sponsored by the Eastern Nursing Research Society will be held on April 26-27, 1990, at the Roosevelt Hotel in New York City, hosted by City, Hunter, and Lehman Colleges of the City University of New York and Pace University.

The emphasis will be on research and research design leading to the development of nursing science. Abstracts to be considered for presentation must be a summary of research completed at the time of abstract submission. Abstracts for poster sessions may be of completed or ongoing research. Please submit three typewritten copies of the abstract which should be 250-300 words, single-spaced. Abstracts must include the following information: 1) title; 2) purpose of the study; 3) framework; 4) design; 5) subjects; 6) methodology; 7) procedure for analysis; and 8) major findings and conclusions. Designate the research as qualitative, quantitative, or blended. Please include professional credentials and highest degree earned.

Paper presentations will be limited to one presenter, per paper who is a member of the ENRS, although all authors will be acknowledged in the conference program. Presenters will not be reimbursed for expenses.

Send abstracts to: Dr. Keville Frederickson, Research Conference Committee, Division of Nursing, Lehman College of CUNY, Bedford Park Blvd. West, Bronx, NY $10468,212-960-8378$. Deadline for submission of abstracts is October 1,1990 .

\section{PEPLAU'S BOOK NOW AVAILABLE}

Interpersonal Relations in Nursing, by Hildegard E. Peplau, RN; EdD, Prof essor Emerita, Rutgers University, has been republished by Macmillan Education Ltd., London. The forward for this 309-page paperback is by Trevor Clay, General Secretary, The Royal College of Nursing, U.K. To order this book (order no. ISBN 0-333461 12-6), contact Mary Waltham. Medical Division Macmillan Education Ltd., Houndsmills Basingstoke Hampshire RG21 2XS, England. (Price is about \$9.00 U.S.) 